derness, no rigidity. Recovery was slow. A few months after this he had a second attack similar in every way to the first except that the pain was at the margin of ribs in mid-axillary line. The physicians called pronounced this hepatic abscess. The patient again refused operation and recovery ensued.

Examination.-On June 5, 1909, I found the patient suffering from agonizing pain, confined to the right nephritic region, headache, nausea, vomiting and great nervousness. There was some slight discoloration of the conjunctivæ; pulse was 68; temperature, 98.3 ; some slight tenderness over point of pain but no radiation. There was no rigidity. The kidney was not palpable; the liver was normal in size. Hot applications failed to relieve pain, and morphin was given. Urine was scanty, highly colored, depositing a heavy sediment on standing; sp. gr. 1028, acid, no albumin or sugar. Microscope gave quantities of mixed urates and uric acid crystals; no pus or blood cells. Blood count was normal. The Garrod string test was not applied.

Treatment.--.This consisted in relieving the constipation by means of alkaline diuretics, careful dieting and copious draughts of water. Recovery was rapid and the patient states that he feels better than for the past year.

It will be noted that in no attack did he have fever, rapid pulse, pronounced tenderness or any rigidity; that headache, nausea, vomiting and extreme nervousness accompanied all and that each attack was preceded by constipation, headache and scanty, highly colored urine.

Such cases are interesting, not from their rarity, but from a diagnostic standpoint. We are too prone to consider every abdominal pain as indicative of appendicitis, cholelithiasis or ureteral calculus.

The periodic attacks of arthritis are entirely relieved by the salicylates, alkaline diuretics and hot applications. These attacks are not necessarily coincident with the other affection, but has given him some trouble during the last attack. The facial neuralgia has given the patient no trouble since the first attack of the present trouble.

\section{TUBERCLE BACILLI IN THE BLOOD}

\section{ORLANDO H. PETTY, M.D.}

\section{AND}

A. M. MENDENHALL, M.D.

Pathologist and Resident Pathologist, respectively, St. Timothy's Hospital

PHILADELPHIA

Drs. M. P. Ravenel and Karl W. Smith of Madison report $^{1}$ eighteen cases of tuberculous patients whose blood they examined by the Rosenberger method; they failed to demonstrate tubercle bacillus in the blood of a single case, and conclude: "This investigation has been confirmed by reports from all over the world, and the only conclusion that can be reached is that the Rosenberger method is of no value."

We wish to report ten such examinations, a number quite too small to warrant us in criticizing such an authoritative and conservative worker as Rosenberger, yet sufficient, we think, to permit us to question the above results and conclusions.

CaSE 1.-Clinical diagnosis, pulmonary tubereulosis; bacillary sputum.

Blood examination: Some microscopic fields, no tubercle bacilli; others had various numbers, the highest being nineteen in one field.

CASE 2.-Patient had hip-joint disease three years before coming under observation, abscess formation; operation, recovery with fixation; $x$-ray shows partial destruction of head of femur and acetabulum. Physical examination and clinical symptoms negative.

Blood examination: Tubercle bacilli as high as nine in field.

1. Proccedings of the State Medical Society of Wisconsin, reported in Tre Jouria A. M. A., Aug. 21, 1909, liii, 649 .
CASE 3.-Clinical and physical signs of pulmonary tuberculosis; sputum non-bacillary.

Blood examination: As many as 6 bacilli in one field.

CASE 4.-A child with hip trouble; $x$-ray negative for osseous destruction. Physical examination negative.

Blood examination: Tubercle bacilli in blood.

CASE 5.-A young man, now apparently healthy, although two years before coming under observation he was very much "run down." Afternoon and evening temperature as high as $101 \mathrm{~F}$; cough and loss of weight. Physical examination at that time and present, negative. Dozens of sputum examinations, also examinations of urine and feces, negative for tubercle bacilli.

Blood examination: As high as 10 tubercle bacilli in a field. CASE 6.-A patient with axillary adenitis. Pathologic re. port on removed glands, sarcoma.

Blood examination: Negative for tuberele bacilli.

CASES 7 and 8.-Positive findings. A diagnosis of typhoid fever has been made since. One of these cases at least is clinically typhoid. In each of these cases several hours' search revealed only a few bacilli.

GASE 9.-This ease had a provisional diagnosis of tabes dorsalis with an unexplainable temperature.

Blood examination: Positive for tubercle bacilli.

CASE 10.-Pulmonary tuberculosis; bacillary sputum.

Blood examination: Positive.

Our technic is Rosenberger's improvement on what he originally used. 'The venous blood is smeared rather thickly on cleaned slides, dried, laked in distilled water, fixed, then stained with gently heated carbol fuchsin fos five minutes, washed with water, decolorized with 25 per: cent. nitric or sulphuric acid, then stained with methylene blue, or with Gabbet's solution used immediately after the carbol fuchsin. There is no doubt but that morphologically and tinctorially these were tubercle bacilli. If this technic does not demonstrate that these were not tubercle bacilli, then one cannot make a positive diagnosis of bacillary sputum without inoculation tests.

We do not wish to go on record as to the practical value of the Rosenberger method, but report our findings to encourage others to continue their labors, for the subject certainly can not be considered a closed one.

\section{New and Nonofficial Remedies}

Since the publication of the book "New and Nonofficiad REMEDIES, 1909," THE FOLLOWING ARTICLES IIAVE BEEN ACCepted by tile Council on Pharmacy and Chemistry of the amertcan Medical association. Their acceptance has BEEN BASED LARGELY ON EVIDENCE SUPPLIED BY THE MANUFACTURER OR IIS AGENT AND IN PART ON INVESTIGATION MADE BY OR UNDER THE DIRECTION OF THE COUNCIL. Criticisms and CORRECTIONS TO AID IN THE REVISION OF THE MATTER BEFORE PUBLICATION IN THE BOOK ARE ASKED FOR.

The CounCIL DESIRES PHYSICIANS TO UNDERSTAND THAT THE ACCEPTANCE OF AN ARTICLE DOES NOT NECESSARIIY MEAN A RECOMMENDATION, BUT THAT SO FAR AS KNOWN IT COMPLIES WITH THE RULES ADOPTED BY THE COUNCIL.

\section{W. A. PUCKNER, Secretary.}

\section{TRANSFER OF AGENCY}

Triferrin and Triferrol (see New and Nonofficial Remedies, 1909 , p. 134 and 135), formerly sold by C. Bischoff \& Co., New York, are now sold by Knoll \& Co., New York.

MASSOLIN - Cultura Bacilli Bulgarici-Lederle.-Massolin is a pure culture of the Bacillus bulgaricus of Massol, grown on one of the following media: Calcium carbonate lactose broth, calcium carbonate dextrose broth, calcium carbonate Cohendy broth, or Cohendy broth.

The material for one of the above broths is sterilized for thirty minutes on three successive days and then placed in the incubator for at least forty-eight hours to determine its sterility before using. The material is then put into large flasks, inoculated from test tube cultures of the bacillus and incubated at $37 \mathrm{C}$. (98.5 F.) for from twenty-four to ninety-six hours. It is then tested to see that it is free from contaminating orisanisms.

The preparation is of an amber color and has the odor and taste of the particular medium employed as its base. 